\title{
A Qualitative Descriptive Analysis of Collaboration Technology in the Navy
}

\author{
Ryan Wark and Jon Webber \\ University of Phoenix, Phoenix, AZ, USA
}

warkr@san.rr.com drjonwebber@gmail.com

\begin{abstract}
Collaboration technologies enable people to communicate and use information to make organizational decisions. The United States Navy refers to this concept as information dominance. Various collaboration technologies are used by the Navy to achieve this mission. This qualitative descriptive study objectively examined how a matrix oriented Navy activity perceived an implemented collaboration technology. These insights were used to determine whether a specific collaboration technology achieved a mission of information dominance. The study used six collaboration themes as a foundation to include: (a) Cultural intelligence, (b) Communication, (c) Capability, (d) Coordination, (e) Cooperation, and (f) Convergence. It was concluded that collaboration technology was mostly perceived well and helped to achieve some levels of information dominance. Collaboration technology improvement areas included bringing greater awareness to the collaboration technology, revamping the look and feel of the user interface, centrally paying for user and storage fees, incorporating more process management tools, strategically considering a Continuity of Operations, and incorporating additional industry best practices for data structures. Emerging themes of collaboration were collected to examine common patterns identified in the collected data. Emerging themes included acceptance, awareness, search, scope, content, value, tools, system performance, implementation, training, support, usage, structure, complexity, approach, governance/configuration management/policy, and resourcing.
\end{abstract}

Keywords: Government, Business Intelligence, Collaboration, Information Technology, Ecollaboration

\section{Introduction}

At the rise of the information age, the term "knowledge worker" was coined as a unique class of highly educated experts using their minds as the primary tools. Drucker (1954, as cited in Mládková, 2011) described a knowledge worker as a unique person with important knowledge to the organization, a user of knowledge, and a person who works intellectually. As the Information Age emerged with the onset of computers, the number of knowledge workers increased

Material published as part of this publication, either on-line or in print, is copyrighted by the Informing Science Institute. Permission to make digital or paper copy of part or all of these works for personal or classroom use is granted without fee provided that the copies are not made or distributed for profit or commercial advantage AND that copies 1) bear this notice in full and 2) give the full citation on the first page. It is permissible to abstract these works so long as credit is given. To copy in all other cases or to republish or to post on a server or to redistribute to lists requires specific permission and payment of a fee. Contact Publisher@,InformingScience.org to request redistribution permission.
(McNurlin, Sprague, \& Bui, 2009). In 1957, the number of the United States jobs with a function of handling information (information workers) exceeded the number of industrial workers (McNurlin et al.). In 1980, the number of the United States information workers passed all other working sector positions combined (McNurlin et al.). 
The knowledge worker in today's organizations is often part of a flat or horizontal structure. This type of organizational structure usually is identified as a functional, divisional, or matrix (Bateman \& Snell, 2007). According to Bateman and Snell, "in a functional organization, jobs (and departments) are specialized and grouped according to business functions and the skills they require: production, marketing, human resources, research and development, finance, accounting, and so forth" (p. 271). In a divisional organization, departments are categorized based on group or units tied to the products, clients, or geographic regions (Bateman \& Snell). The matrix organization emerged from the government aerospace industry in the 1960s (Bateman \& Snell). A matrix organization often includes a hybrid of both functional and divisional structures where employees report to two supervisors (Bateman \& Snell). The approach suggested a government matrix organization might leverage resources and capitalize on specialty functions (Bateman \& Snell).

There are several benefits associated with a matrix type organization. The benefits include the ability to leverage people and resources, the ability for an organization to develop autonomy from external influences, and an improved ability to sway other entities (Baber \& Bartlett, 1990). Additional benefits include a more effective completion of tasks, improvements of employee satisfaction, and a more defined personal commitment to the organization (Baber \& Bartlett).

There are also several challenges with a matrix type organization. Strikwerda and Stoelhorst (2009) recognized "you cannot run a company like this along a single dimension, you need to manage along multiple dimensions - but one thing is for sure, I never again want to work with a matrix organization" (p. 16). Janićijević and Aleksić (2007) highlighted five challenges of a contemporary matrix organization. These challenges include "(1) misaligned goals, (2) unclear roles and responsibilities, (3) ambiguous authority, (4) lack of a matrix guardian, and (5) silo-focused employees" (p.33).

In alignment with efficiency goals, one United States Navy activity embraced a culture of savings through the implementation of a matrix-oriented Competency Aligned Organization. A Navy matrix organization incurs a high risk for ineffective collaboration. This risk diverts from a mission of information dominance. U.S. Fleet Cyber Command (2012) defined information dominance as "the operational advantage gained when the Navy's informational functions, capabilities, resources, and people are integrated to the extent that decision-making and its corresponding warfighting effects are not only optimized, but superior to our adversaries" (p. iii). Information dominance requires synchronous collaboration to leverage resources and information generating quick and accurate decisions.

Collaboration across an organization should benefit from a technology able to collect, store, categorize, and use data in making quick and accurate decisions. Well-orchestrated collaboration technology provides the ability to deliver the right information to stakeholders in a timely and accurate manner. Shengin and Bo (2011) suggested a positive technology capability leads to a positive influence on innovation success, leading to a positive influence on organizational productivity.

Collaboration technology often incorporates tools for making decisions. This concept is similar to the Navy mission of information dominance. Industry refers to this concept as business intelligence (Jucevicius, 2011). Business Intelligence systems are able to use collaboration technology to organize intellectual information. This information can then be used to develop perceived decisions regarding the environment based on reasons and effects rational (Jucevicius). Adding the use of clustered networks and mechanisms can create new perceptions of the business environment by integrating new knowledge from intellectual capital (Jucevicius).

A business intelligence system creates value through the collection of data, categorization of data, and display of useful information (Jucevicius). Jucevicius described the following three criteria 
that enable this process. First, the organization should understand the potential use of knowledge and technology to improve productivity. Second, the infrastructure should combine knowledge with technology. Third, an effective business intelligence system enables the connection of knowledgeable resources with a virtual space for innovation. Poorly implemented collaboration technology has the potential to impose a significant burden to organizations. Gartner (2009) predicted that in $201235 \%$ of the top 5000 global companies would make incorrect decisions using information systems. Poor decisions lead to unnecessary burdens for an organization, resulting in high cost, low productivity, and indecisive decisions leading to a competitive disadvantage (Gartner).

The challenges of a matrix organization and poor implementation of collaboration technology acknowledge a common element of ineffective collaboration. Nemiro, Beyerlein, Bradley, and Beyerlein (2008) defined effective collaboration as "the collective work of two or more individuals where the work is undertaken with a sense of shared purpose and direction that is attentive, responsive, and adaptive to the environment" (p. 1). Brake (2009) discovered effective collaboration requires six collaboration performance zones. These performance zones include (a) cultural intelligence, (b) communication, (c) capability, (d) coordination, (e) cooperation, and (f) convergence.

The specific purpose of this qualitative descriptive study was to examine how a matrix oriented Navy activity perceived an implemented collaboration technology. These perceptions were used to determine whether a specific collaboration technology achieved a mission of information dominance. The study used six collaboration themes as a foundation to include the following: (a) Cultural intelligence, (b) Communication, (c) Capability, (d) Coordination, (e) Cooperation, and (f) Convergence.

\section{Collaboration Themes}

\section{Cultural Intelligence}

Teams require the acknowledgement of cultural and organizational values to operate effectively in a collaboration environment (Brake, 2009). These values generate closeness and creativity between teams (Mor, Morris, \& Joh, 2013). Cultural intelligence influences heavily strategy and performance in an organization (Magnusson, Westjohn, Semenov, Randrianasolo, \& Zdravkovic, 2013). This performance enables competitive advantage (Sawhney, 2008). Cultural intelligence often associates with international interactions (Eisenberg et al., 2013); however, this study more specifically compares, contrasts, and evaluates several theories aligning with the organizational cultural interactions of a Navy matrix organization.

\section{Communication}

An organization culture embracing positive behavior eases communication processes (French \& Holden, 2012). The absence of communication processes produces alteration in the organizational culture (Daniela, 2013). Technology provides the capacity to embrace positive behavior and communicate information over distances (Brake, 2009). Information across local and global boundaries has become a driving force for knowledge workers, enabling teams to achieve rapid far-flung communication (McNurlin et al., 2009). Strang et al. (2011) identified strong correlation between successful communication and collaboration technologies in military operations. Successful Communication drives efficiencies into organization processes (Nicolau, 2013) and produces clarity between leadership and employees (Mishra, Boynton, \& Mishra, 2014). 


\section{Capability}

Virtual collaboration technologies allow knowledge workers to achieve a greater sense of "being there" thus improving information processing (Van der Land, Schouten, Van den Hooff, \& Feldberg, 2011). Brake cataloged capability as the "ability to leverage the knowledge, skills, and experience of all members, and increase the capability of the team as a whole" (p. 14). Technology provides a key element to increase transactional capability (Zawislak, Alves, Tello-Gamarra, Barbieux, \& Reichert, 2012) and advances organizational performance (Allred, Fawcett, Wallin, \& Magnan, 2011). Organizations vesting low in collaboration technologies procure insignificant returns (Morgan, Autry, \& Adams, 2012). Improving collaboration technologies helps organizations to achieve strategic objectives (Morgan et al., 2012).

\section{Coordination}

Collaboration technologies are not always successful in achieving strategic objectives (Elbashir, Collier, Sutton, Davern, \& Leech, 2013). Implementing a new technology capability requires proper planning and training. This planning should lead to synchronous, coherent, and continuous behavior. In terms of virtual teams, technology implementation requires a set of operating rules orchestrating individual behavior roles as well as the shared tools, processes, and method (Brake, 2009). A well-coordinated knowledge management process often provides the set of operating instructions and guidelines to achieve strategic objectives (Gudas, 2009).

\section{Cooperation}

Knowledge management activities prove to be a complex task (Yang \& Benrard, 2010). Collaboration technologies require resourcing commitments and proper coordination of organizational interest (Gulati, Wohlgezogen, \& Zhelyazkov, 2012). Once commitment and coordination have been established, complexities of trust exist. Collaboration technology requires the ability for resources to trust the exchange of information to achieve a common goal (Msanjila \& Afsarmanesh, 2008). Cooperation necessitates virtual teams trust one another across geographies, time themes, and cultures (Brake, 2009). Trust develops over a period of time between workers (Sarkus, 2013). Trust provides the foundation of successful teams and members should take personnel responsibility for building trust (Lees, 2011).

\section{Convergence}

Typically, knowledge activities are not well defined resulting in an ad-hoc environment (Yang \& Benrard, 2010). Collaboration technology requires purposes and directives (Brake, 2009).

Thomas (2011) defined convergence as an "approach toward a definite value, a definite point, a common view or opinion, or toward a fixed or equilibrium state" (para. 1). Collaboration technology success depends upon the willingness and participation of individual in the organization.

\section{Collaboration Technologies}

Knowledge workers conduct business using collaboration technologies. Currier (2010) found collaboration tools have changed just over the last decade. Currier referenced the director of Pricewaterhouse Coopers' Advisory Panel:

A decade ago, we saw the emergence of collaboration as standalone tools that worked with search technologies, document management tools, etc. Today, we are seeing a convergence of these technologies, whereby document management, collaboration/social networking and process management activities are forming a new breed of knowledge worker enablement tools. (p. 23) 
Currier (2010) surveyed 342 managers knowledgeable about their use of collaboration tools in their company. Shared calendars rate at the top of collaboration tools with $70 \%$ of the knowledge workers using this tool to collaborate. Shared calendars provide a simple and effective tool for knowledge workers to communicate about meetings and events among the organization. The knowledge worker takes advantage of data repositories to share documents and files. Web conferencing and portals also provide a significant percentage of the collaboration tools used by the knowledge worker. Collaboration tools are essential to increasing the productivity of the knowledge workers, remote users, and provide a point of access to organization resources using a service-oriented architecture (Geczy, Izumi, \& Hasida, 2011).

Collaboration technologies provide the foundation for information dominance success. Several platforms exist, such as Microsoft's ${ }^{\circledR}$ SharePoint ${ }^{\circledR}$ (Rapoza, 2010). Rapoza described many features of SharePoint ${ }^{\circledR}$. Features include a portal used for business-oriented social networking and document management. SharePoint ${ }^{\circledR}$ provides a commercial out of the box platform for virtual teams to collaborate in and share information Microsoft's ${ }^{\circledR}$ SharePoint ${ }^{\circledR}$ interoperates well with other Microsoft ${ }^{\circledR}$ products, such as Word $\AA$, Excel ${ }^{\circledR}$, PowerPoint ${ }^{\circledR}$, Access ${ }^{\circledR}$, and Outlook ${ }^{\circledR}$ (Rapoza). All these applications have SharePoint ${ }^{\circledR}$ functionality built into the product, and SharePoint ${ }^{\circledR}$ essentially becomes the cloud enabling collaboration. Key features of Microsoft's $\mathrm{R}$ SharePoint ${ }^{\circledR}$ includes the following

- "Granular permissions" allowing users to only view information authorized to see.

- Permission based "targeted content"

- A powerful search engine

- Use of content types to describe and classify metadata

- Customized "My Site" areas for specific user. The site can be organized in any way the end user desires. This organization includes the pull of information into web parts (Ennis \& Tims, 2010).

IBM ${ }^{\circledR}$ Connections ${ }^{\circledR}$ provides another platform consisting of social 2.0 tools for organizations to collaborate (IBM, n.d.). The secure platform has an objective to align people in the organization with business experts leading to greater innovation (IBM, n.d.). IBM ${ }^{\circledR}$ Connections offers the ability to:

- Integrate social and business processes

- Social analytics

- Deliver to virtually any mobile device

- Integration with third-party applications (IBM, n.d.)

HyperOffice ${ }^{\circledR}$ provides another platform accommodating organizational collaboration in small to medium sized businesses (HyperOffice, 2013). Similar to SharePoint ${ }^{\circledR}$, HyperOffice ${ }^{\circledR}$ provides various social 2.0 tools, online document management, online calendars, and project management functionality (HyperOffice). This tool has some interoperability with productivity tools such as Microsoft ${ }^{\circledR}$ Outlook ${ }^{\circledR}$ and users have the ability to customize pages (HyperOffice).

Collaboration technology has the ability to interoperate with other enterprise systems through autonomous and intelligent networking (Paschke \& Martin, 2008). Autonomous and intelligent networks automatically draw inferences or relationships between several pieces of complex information in the database (Paschke \& Martin). Paschke and Martin demonstrated an example of the need to draw automated inferences between predefined service level agreements. The intelligent network provides automated rule chaining allowing a flexible knowledge environment adaptable to changing business requirements. 
Automated inferences derive from basic search engines used on the Internet and business intranets (Martinez, Pastor, Rodriquez, Lopez, \& Rodriquez, 2011). Microsoft's ${ }^{\circledR}$ SharePoint ${ }^{\circledR}$ and other websites such as Facebook ${ }^{\circledR}$, Google ${ }^{\circledR}$, and Yahoo ${ }^{\circledR}$ use search engines to draw interferences between search topics based on keywords and Boolean variables (Martinez et al., 2011). Martinez et al. asserted, "search engines have been, currently are, and in all probability will continue to be the most popular systems in this information cosmos" (para. 1).

Collaboration technologies may require a massive increase in data storage and information repositories (Szczerbicki, 2006). Szczerbicki indicated, "information and knowledge management are two of the most important aspects to be considered in modern intelligent systems development" (p. 93). Szczerbicki outlined some of the advances in providing intelligent knowledge management in collaboration technology. These advances include rule driven messaging, information filtering, experience driven information, integrated processes, ergonomic adjustments, and personalized search.

\section{Methodology}

This study related to the neo-modernist reflexive, reflective, and the media naturalness theories. A number of writers developed the reflexive theory, based on the critical theory, in the 1980s expanding on some the earlier ideas of Marx, Weber, Freud, and German philosophers such as Kant (McAuley, Duberley, \& Johnson, 2007). Fundamental questions were asked about how humans experience reality (McAuley et al.). Researchers further elaborated into how humans experience reality, addressed issues of organizational life, and expanded on the ways humans act collectively, giving meaning to their lives in an organization (McAuley et al.).

Schon (1983, 1987, 1991 as cited in McAuley et al. developed the reflective theory as documented in The Reflective Practitioner. Schon recognized the need to reflect deeper on organizational reality and life issues (McAuley et al.). Focus was given to the use and interpretation of empirical information collected from the organization (McAuley et al.).

Researchers began to evaluate function allocations between humans and machines. A method developed by Fitts (1951 as cited in Waterson, Older, Gray, \& Clegg, 2002) provided a comparison between the tasks the human was better at performing against the functions a machine was better at performing. This method became widely used to determine appropriate working allocations for organizations (Watersonet al., 2002).

The media naturalness theory identified challenges associated with the adoption of collaboration technology for humans (Kock, 2008). The theory depicted humans as requiring five basic elements to communicate in an organization (Kock). These elements include the need for individuals to see and hear one another, interact quickly, send and receive facial expressions, convey and observe body language, and send and receive speech (Kock, 2002). D'Urso and Rains (2008) referred to the theory of channel expansion and identified three components to media richness including perceptions of experiences, the message conveyed, and the medium used for communication. Kwak (2012) emphasized communicating with computers reduces the quality of information conveyed (i.e., Media Richness Theory).

Other research found differences between distributed work tools and collaboration environments in which information processing support tools are used (Brown, Dennis, \& Venkatesh, 2010). Identified were limits in the number of models available to measure the integration of knowledge from technology and the lack of collaboration technology research (Brown et al.).

Collaboration themes provided the foundational framework to develop a qualitative descriptive study. A qualitative descriptive study provided a method to capture collaboration technology perceptions. Human perceptions require the use of qualitative methods to describe measures of 
experiences accurately (Leedy \& Ormrod, 2010). The categorization of perceptions encourages subjective results and inductive reasoning (Leedy \& Ormrod). Leedy and Ormrod suggested the qualitative approach provides an appropriate method to draw inferences about several observations. A descriptive element to the study provided predefined characteristics of the collaboration technology and the Navy population (Jansen, 2010).

A qualitative study enabled an analysis of positive and negative perceptions related to collaboration technology (Krebbekx, Harting, \& Stronks, 2012). The study incorporated descriptive measures and does not use statistical analysis to determine whether a central tendency exists. Christensen, Johnson, and Turner (2010) suggested qualitative research provides a more appropriate method for describing situations and developing theory; whereas, quantitative research provides a more appropriate method for hypothesis testing.

A survey instrument was developed consisting of 20 questions. The first seven questions were multiple choices and collected demographic information such as the affiliation, portfolio, competency assigned, functional position, gender, age, and experience. Questions 8 through 13 were open-ended and asked the user to describe positive and negative collaboration experiences using technology. Collaboration experiences are associated with the six initial themes. These experiences include (a) cultural intelligence, (b) communication, (c) capability, (d) coordination, (e) cooperation, and (f) convergence (Brake, 2009). Questions 14 through 19 were also open-ended questions and ask the user to describe any suggested modifications required to improve the collaboration technology. These questions were also associated with the six themes of collaboration. Question 20 provided a general open-ended question to identify any other comments or suggestions regarding the collaboration technology.

A pilot study was conducted to determine whether the survey instrument delivered the desired results and if any questions were misinterpreted. An objective of the pilot study was to measure the quality level of the queries and estimate the time to take the instrument (SurveyMonkey, 2013). The pilot study provided an opportunity to run through the course of the study prior to data collection and make any necessary changes.

Five volunteers across the competencies participated in the survey. Corrections to the survey were made upon the identification of discrepancies. The changes were not significant and a second pilot survey was not necessary. The pilot checklist guided the pilot study. Navy participants partaking in the pilot survey did not take the production survey.

NVivo10® software provided a qualitative and powerful capability to analyze data using search, query, and visualization tools, allowing subtle connections and the generation of insights and ideas to justify findings (QSR, 2013). The output of NVivo10® produced analytics identifying themes and patterns. Conclusions were then drawn regarding perceptions of the collaboration technology.

NVivo10® uses several key concepts to categorize information. QSR (2014) categorizes information into sources, coding, nodes, and node classifications. Sources refer to the research material used in the study. Coding enabled the tagging and gathering of information by topic, theme, or case. Nodes provided containers of gathered codes aligning with a common pattern. Node classifications categorized demographic type information about the survey participants.

The coding process involved identifying patterns of data aligned with the initial six collaboration nodes. Positive, negative, neutral, and improvement themes were coded against each collaboration theme. Several queries and reports were then used to compare various data patterns. The queries were used to identify how many coded references and the percentage of coding assigned to various nodes. 


\section{Findings}

This qualitative descriptive study had an objective to examine how matrix oriented Navy personnel perceived an implementation of collaboration technology. Literature identified limits in the number of models available to measure the integration of knowledge from technology and the lack of collaboration technology research (Brown et al., 2010). This study provides a means to measure the integration of knowledge from technology based on perception. Two research questions guided this study:

- What positive or negative themes are associated with the experiences of those who use the collaboration technology?

- What improvement themes are associated with the experiences of those who use the collaboration technology?

The population consisted of 650 Navy users of the collaboration technology as of March 2014. In quantitative research, an appropriate sample size needs to be representative of the population and generalized (Christensen et al., 2010). Qualitative sample sizes, however, are generally small and do not always represent the perspectives of the entire population (Brikci \& Green, 2007). This study incorporated 25 collaboration technology users across the competencies. The sample size of 25 anticipated three users from each of the eight competencies plus at least one portfolio manager.

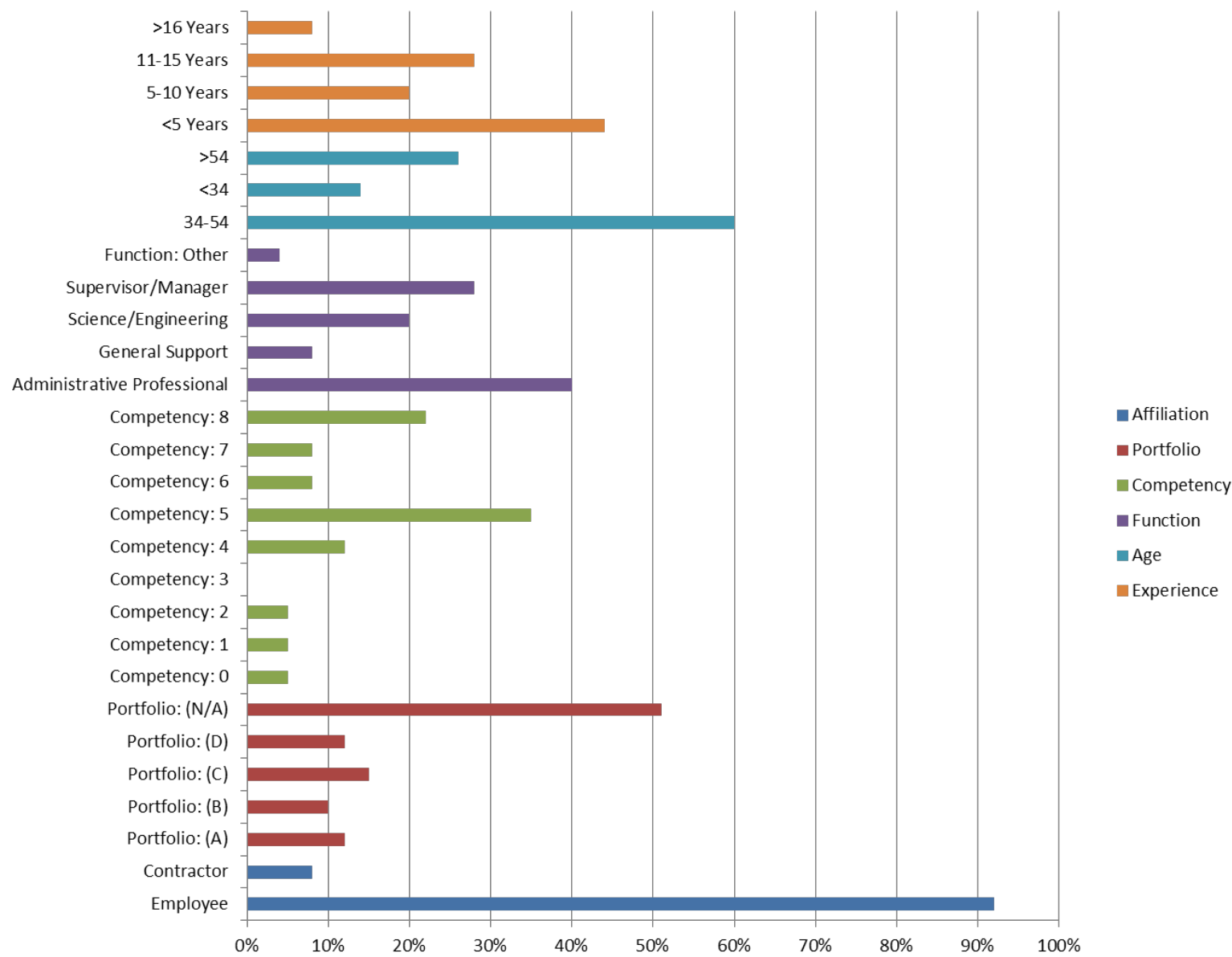

Figure 1. Percentage of total sample for each demographic classification. 
Demographic information was collected and classified into cases in the NVivo10® software. Demographic information included Navy affiliation, portfolio, competency assigned, functional position, gender, age, and length of experience. The data was transcribed into percentage of the total sample for each demographic classification. Figure 1 summarizes the collected demographic information.

In alignment with Research Question 1, positive and negative coded references were identified. There were 110 positive coded references of Navy collaboration technology users. These coded references showed the collaboration technology was perceived well, thus enabling a mission of information dominance. Top positive themes included capability, cultural intelligence, and cooperation. There were 107 negative coded references of Navy collaboration technology users. Top negative themes included coordination, convergence, and communication. These coded references showed the collaboration technology was not perceived well, thus limiting a mission of information dominance. It was concluded collaboration technology was mostly perceived well and helped to achieve some levels of information dominance.

In alignment with Research Question 2, there were 169 improvement-coded references. Top improvement areas included capability, convergence, and cooperation. Figure 2 summarizes the positive, neutral, negative, and improvement coded references associated with the six collaboration themes.

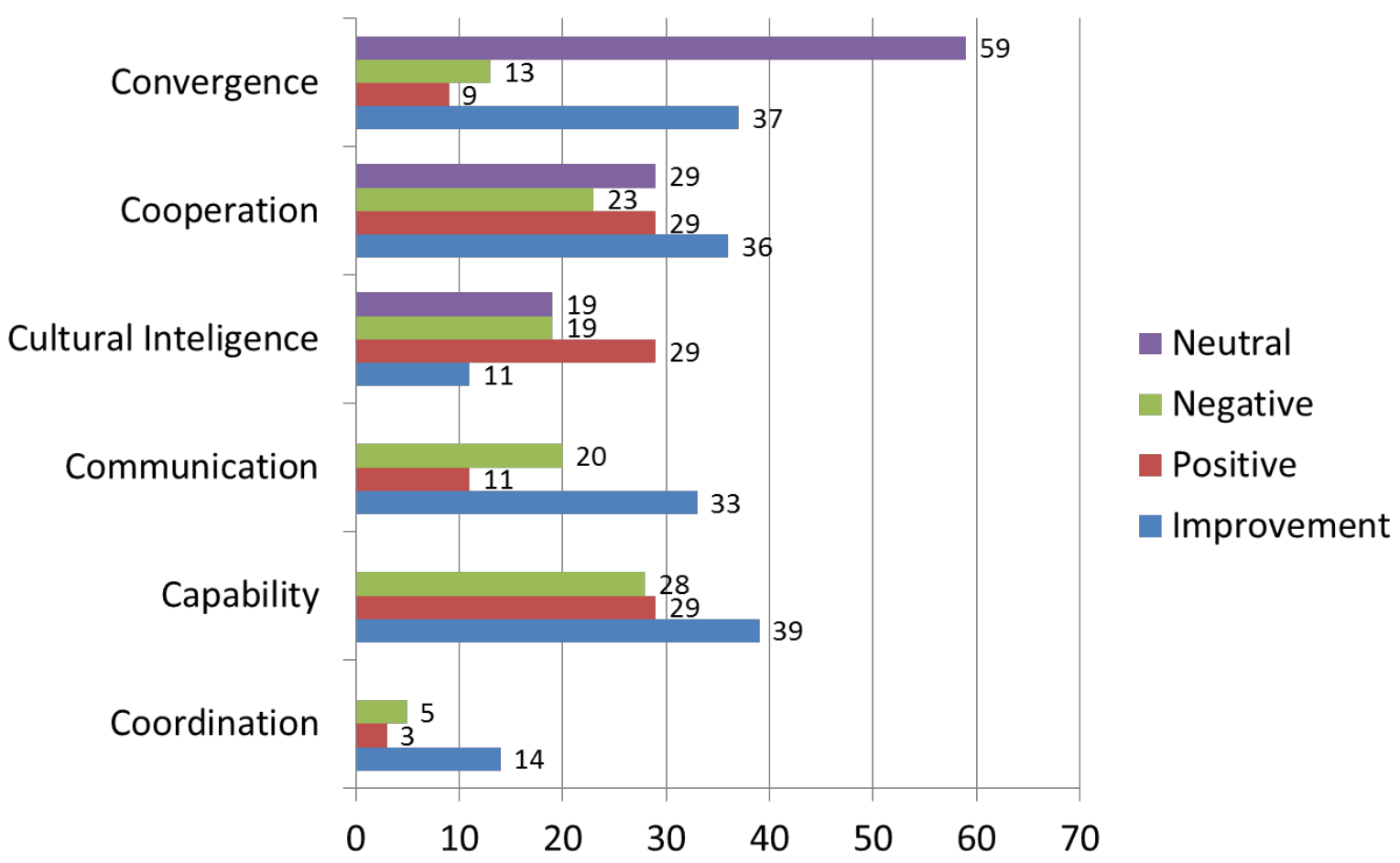

Figure 2. Positive, neutral, negative and improvement coded references associated with the six collaboration themes.

The degrees to which these improvements are creditable were significant, but were somewhat limited by the high amount of neutral coded themes. There were no resource limitations identified during the course of the study. The data demonstrated a balanced representation across organizational activities, business portfolios, competencies, function, gender, age, and experience. 


\section{Discussion}

Collaboration themes were used to determine how Navy users perceived the collaboration technology. Emerging themes of collaboration were collected to examine common patterns identified in the collected data. Using NVivo10®, 17 new emerging themes were identified. The theme of cultural intelligence associated with emerging themes of acceptance and awareness. Communication associated with emerging themes of search, scope, and content. Capability associated with emerging themes of value, tools, and system performance. Coordination associated with emerging themes of implementation, training, and support. Cooperation associated with emerging themes of usage, structure, and complexity. Convergence associated with emerging themes of approach, governance/configuration management/policy, and resourcing. Figure 3 summarizes emerging themes from highest to lowest coded references.

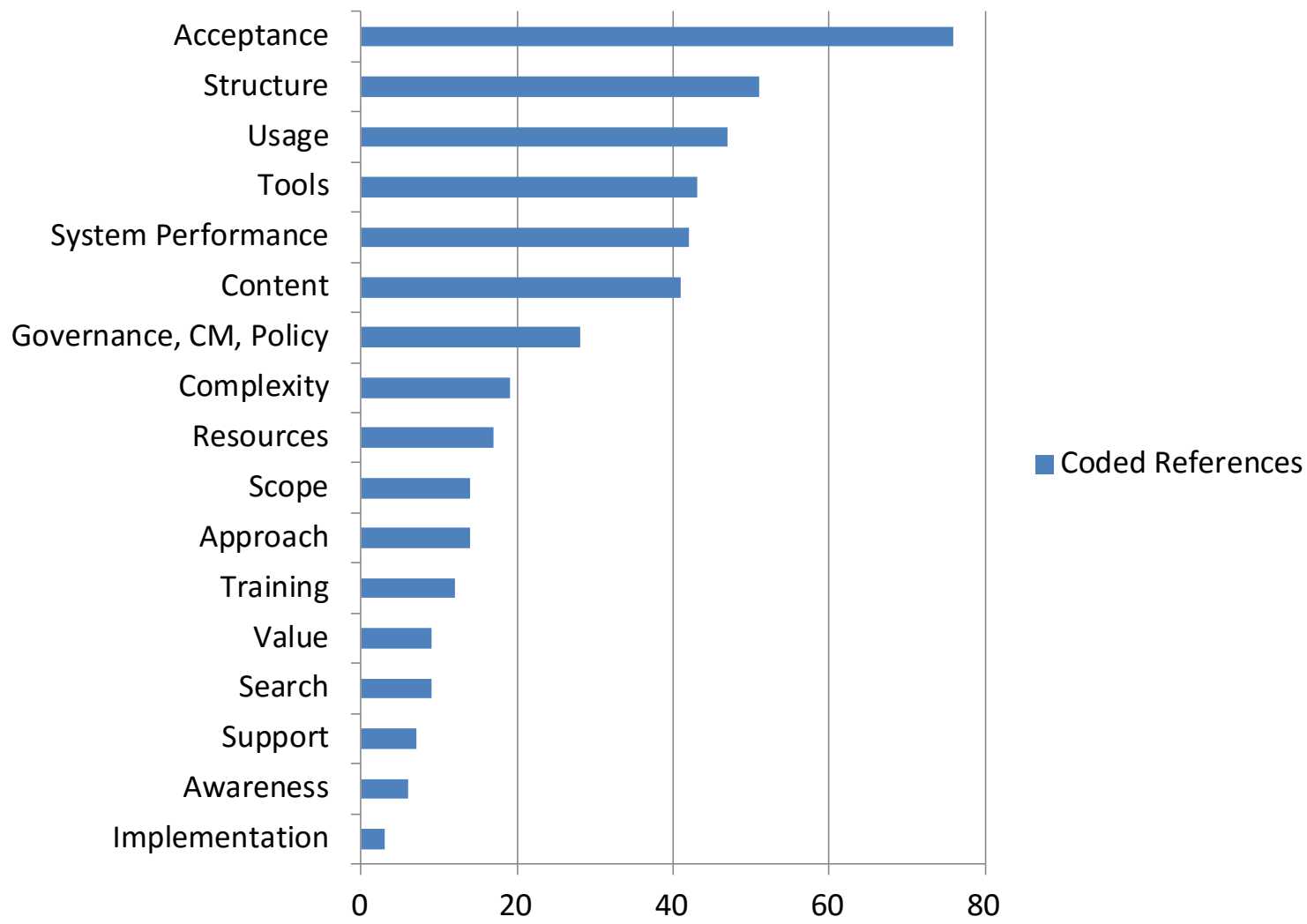

Figure 3. Summary of emerging themes from highest to lowest coded references

\section{Awareness}

The emerging theme of awareness provided six coded references under the cultural intelligence theme. Awareness aligns with the ability for organization to be cognizant of the collaboration technology. Postmodernist or new wave theory suggested subordinates have autonomy through empowerment at all levels of the organization. This social influence shapes collaboration technology.

The organization needs to be aware the collaboration technology exists. Demonstrating the collaboration technology at all organizational levels should increase the overall acceptance. Special focus should be given to business intelligence aspects of the collaboration technology. 


\section{Acceptance}

The emerging theme of acceptance had over 76 coded references under the cultural intelligence theme. Acceptance suggests the willingness of the organization to use the collaboration technology. Acceptance aligns with several socio-clinical studies. Trist and Bamforth were hired to study the low productivity in the mines despite the use of technology (Iles, 2011). One study focused on group relations throughout the organization (Trist, 1981). The other study evaluated the work practices not requiring working capital expenditures (Trist). The studies concluded technology negatively influenced employees leading to discontent and absenteeism (Iles, 2011).

Acceptance requires teams to be inclusive of values in the virtual workplace (Brake, 2009). Global teams may require the acknowledgement of certain cultural or organizational values to operate effectively in a collaboration environment. Demonstrating the unique value of the collaboration technology at all levels of the organization will help to improve acceptance.

\section{Approach}

The emerging theme of approach provided 14 coded references under the convergence theme. Thomas (2011) described approach as movement "toward a definite value, a definite point, a common view or opinion, or toward a fixed or equilibrium state" (para. 1). Collaboration technology depends upon the participation of individual performance and the ability to correlate several sub-tasks in fulfillment of a common goal.

Providing a clear measurable vision with goals and value stream will improve the approach. Biesdorf, Court, \& Willmott (2013) stated, "it may sound obvious, but in our experience, the missing step for most companies is spending the time required to create a simple plan for how data, analytics, frontline tools, and people come together to create business value" (p. 6). Guillemette and Paré (2012) concluded, "because changes in organizations and information technology environments are enduring, the alignment of the IT function with business objectives must not only be understood, but constantly renewed and adjusted" (p. 268).

\section{Governance, configuration management, and policy}

The emerging theme of governance, configuration management, and policy provided 28 coded references under the convergence theme. Governance/configuration management/policy considers the restrictive and sensitive environment of government while maintaining communication within the organization and industry partners. Policies, such as a 30-day deactivation policy, are required to maintain proper security posture of the collaboration technology.

COBIT offers a governance tool establishing a balance between policy conformance and performance goals (Mataracioglu \& Ozkan, 2011. Mataracioglu and Ozkan described COBIT as providing conformance to legislation, internal policies, and audit requirements. Performance includes improving profitability, efficiency, effectiveness, and growth. COBIT provides management and a GEIT framework. Mataracioglu and Ozkan indicated, "focus areas are given as strategic alignment, value delivery, risk management, resourcing management and performance measurement" (p. 112). COBIT delivers business benefits and value to the knowledge management enterprise. The tool adds to the value chain by providing increased user satisfaction while complying with local IT policies (Oliver \& Lainhart, 2011).

\section{Resourcing}

The emerging theme of resourcing provided 17 coded references under the convergence theme. Resourcing ensures adequate funding for the technical system. Adequate funding requires proper commitment of organizational interest (Gulati et al., 2012). Investments in collaboration technol- 
ogy should consider several criteria prior to ensuring proper sustainment. These criteria include (a) affordability, (b) savings and competitive advantage, (c) opportunities to deploy new ITenabled processes and products/services, (d) facilitation of information across the organization, and (e) supported requirements by the organization (Peppard, Edwards, \& Lambert 2011).

Requiring end-users to pay for these user and storage services limits the potential of collaboration. Leadership should identify, prioritize, and develop requirements generating the most efficiencies and return on investment. These requirements should be integrated and tracked via a Lean Six Sigma methodology. Documented savings should be reallocated to pay for the fees associated with user accounts and storage. This trickle effect should increase usage, thus increase resourcing.

\section{Implementation}

Implementation provided three coded references under the coordination theme. Implementation requires the chaining of collaboration technologies. Chaining collaboration technology permits knowledge workers to process information as an input to other knowledge systems (Zadjabbari \& Wongthongtham, 2009). Many constraints may limit the chaining of collaboration technology.

Successful implementation of collaboration technology requires several systems to process information in a synchronous, coherent, and continuous manner. Technical links need to be established in a secure manner and policies need to be in place to ensure the sustainment of data. This type of implementation will help to achieve the greater information dominance.

\section{Training}

The emerging theme of training provided 12 coded references under the coordination theme. Training ensures a user of collaboration technology has the appropriate knowledge and skillsets to operate in the collaboration technology environment. The levels of training are dependent upon the type of operations being performed by the user.

All users of the collaboration technology were given basic user training and a few were provided advanced site manager training. However, some features in the collaboration technology are complex. Curriculum needs to simple and easy to recall. Certifications may be necessary for some of the more complex features.

\section{Support}

The emerging theme of support provided seven coded references under the coordination theme. Support ensures the user is able to obtain necessary assistance. The absence of support produces alteration in the organizational culture (Daniela, 2013).

Developing a support webpage creates greater visibility to related issues. The support web pages provide information obtain the appropriate support, status of a trouble ticket, frequently asked questions, and support discussion forums. The support webpage should facilitate efficient corrective action required by a user.

\section{Usage}

The emerging theme of usage provided 47 coded references under the cooperation theme. Usage helps virtual teams trust one another to use the collaboration technology (Brake, 2009). Trust develops over a period of time between workers given there is an increase in commitment and value with the collaboration technology (Sarkus, 2013).

Trust builds through the psychology, sociology, and anthropology components of the organization (McAuley et al., 2007). This ensures the technology properly aligns to the needs of the end- 
user. Including the end-user early in the development process ensures proper humanistic design, thus improving trust.

\section{Structure}

The emerging theme of structure included 51 coded references under the cooperation theme. Structure refers to the indirect cues of the collaboration technology associated with exchanging information. Jensen, Lowry, and Jenkins (2011) provided guidance to improving the structure. Single Detection Theory stated linguistics is a necessary component of credible information. Participation in Decision-Making (PDM) theory incorporated the use of indirect cues from the knowledge worker.

The master page should be adjusted to incorporate linguistic and indirect cures. The left navigation sidebars should incorporate an indirect cue to "expand and collapse" feature. The navigation should include a more linguistic functional approach to organizing the framework. A splash page suggesting a "what do you want to do?" concept could provide an innovative approach to navigating through the collaboration technology.

\section{Complexity}

The emerging theme of complexity provided 19 coded references under the cooperation theme. Complexity provides a measure simplicity or difficulty associated with collaboration technology to exchange information accurately. Knowledge activities prove to be a complex task (Yang \& Benrard, 2010). Many features in collaboration can become confusing and overwhelming for a user

Developing simple form to populate data to a centralized library will create a more simplistic system. Document forms should be intuitive while ensuring proper document upload best practices are achieved. This concept could improve the amount and trust of information available.

\section{Search}

The emerging theme of search provided nine coded references under the communication theme. Search allows a user to quickly and accurately find information using keywords. Identified information should then be displayed in a priority order of most relevant information.

Developing a centralized repository specifically used for search scopes will help locate information. These scopes should be able to distinguish authoritative data. Search results should be refined to include only the information relevant and provide suggestions for further search criteria. The search engine should also take advantage of keywords or tags to better filter information.

\section{Scope}

The emerging theme of scope provided 14 coded references under the communication theme. Scope identifies the local and global boundaries associated with the collaboration technology. Sharing information across local and global boundaries has become a driving force for knowledge workers, enabling teams to achieve rapid far-flung communication (McNurlin et al., 2009). Internal communication provides an important cultural element producing clarity between leadership and employees (Mishra et al., 2014).

Improving the boundaries of information sharing require secure areas to swap large graphical files with outside vendors. Appropriate permission levels and rule sets should automatically delete files or archive data after a defined number of days. Automated workflows should notify recipients a file is available for download and inform the sender when the file has been downloaded. 


\section{Value}

The emerging theme of value provided nine coded references under the capability theme. Value aligns with the ability of the organization to efficiently meet an organization mission of information dominance. Organizations reap significant value through collecting and analyzing information to generate knowledge to make important decisions (Currier, 2010). Currier acknowledged, "by adding collaborative features - or by being added to collaborative applications knowledge management is expanding its capabilities and business value, sometimes dramatically" (p. 23).

A major benefit of collaboration technology activities is the ability to develop value through business intelligence. This business intelligence includes the ability to display meaningful information through the use of metrics, charts, traffic lights, and indicators (Ballou, Heitger, \& Navynell, 2010). These activities should be fully operational and the return on investments should be specifically highlighted.

\section{Tools}

The emerging theme of tools provided 43 coded references under the capability theme. Tools are the applications and features available in the collaboration technology. Collaboration tools provided a key element to increase transactional capability (Zawislak et al., 2012). Collaboration, as a capability, advances organizational performance (Allred et al., 2011).

Attention should be directed to document management, social networking, and process activities (Currier, 2010). Developing tools, such as the contracts repositories, work acceptance tools, and other process trackers in the collaboration technology improve the capability. These tools should help to drive efficiencies in the organization.

\section{System Performance}

The emerging theme of system performance provided 42 coded referenced under the capability theme. System performance considers the ability of the collaboration technology to achieve user expectations. Collaboration technology requires a massive increase in data storage and information repositories (Szczerbicki, 2006). Szczerbicki stated, "information and knowledge management are two of the most important aspects to be considered in modern intelligent systems development, which are expected to solve unforeseen problems, even on the basis of incomplete and imprecise data, information, or knowledge" (p. 93).

The collaboration technology must be able to keep up with the massive increase in data storage and information repositories (Szczerbicki) and the ever-growing demands of end user requirements. Strategic analysis should account for the criticality of the information in the collaboration technology compared against cost. As usage increases, Continuity of Operations should be considered to safeguard information. Other system performance issues, such as login issues and time out issues, need to be resolved by applying the right level expertise.

\section{Content}

The emerging theme of content provided 41 coded references under the communication theme. Content refers to the information available in the collaboration technology. Technology incorporates the capacity to use content across an organization (Brake, 2009).

Information hosted in the collaboration technology should use industry best practices for data structure. Best practices include implementing proper versioning, data tagging, and data achieving features to remove stale data. Centralized repositories should improve the safeguarding of information and the use of data. These centralized repositories should identify levels of infor- 
mation richness (Nemiro et al., 2008) and take advantage of term stores to better organize information.

\section{Conclusion}

This qualitative descriptive study examined how matrix oriented Navy personnel perceived collaboration technology. Benefits of a matrix organization include the ability to leverage people and resources, to be more effective in completion of tasks, higher employee satisfaction, and a more defined personal commitment to the organization (Baber \& Bartlett, 1990). There are also many challenges associated with a matrix organization including the potential for ineffective collaboration (Strikwerda \& Stoelhorst, 2009).

Poorly implemented technology has the potential to impose a significant burden to organizations. Gartner (2009) predicted that in $201235 \%$ of the top 5000 global companies would make incorrect decisions using information systems. Poor decisions lead to unnecessary burdens for an organization, resulting in high cost, low productivity, and indecisive decisions leading to a competitive disadvantage (Gartner).

Literature identified limits in the number of models available to measure the integration of knowledge from technology and the lack of collaboration technology research (Brown et al., 2010). This study provides a means to measure the integration of knowledge from technology based on perception. Two research questions guided this study:

- What positive or negative themes are associated with the experiences of those who use the collaboration technology?

- What improvement themes are associated with the experiences of those who use the collaboration technology?

NVivo10 ${ }^{\circledR}$ software provided a qualitative and powerful data analysis capability. Coding enabled the tagging and gathering of information by topic, theme, or case (QSR, 2014). The coding process identified that collaboration technology was mostly perceived well and helped to achieve some levels of information dominance. Top positive themes included capability, cultural intelligence, and cooperation. Top negative themes included coordination, convergence, and communication. Top improvement areas included capability, convergence, and cooperation.

Further analysis identified 17 new emerging themes. These emerging themes identified recommendations in the areas of governance/CM/policy, approach, resourcing, usage, structure, complexity, acceptance, awareness, search, scope, content, value, tools, system performance, implementation, training, and support. Improvement references aligned with bringing greater awareness of the collaboration technology, revamping the look and feel of the master page, centrally paying for user and storage fees, incorporating additional process management tools, strategically considering a Continuity of Operations, and incorporating industry best practices for data structures.

\section{References}

Allred, C. R., Fawcett, S. E., Wallin, C., \& Magnan, G. M. (2011). A dynamic collaboration capability as a source of competitive advantage. Decision Sciences, 42(1), 129-161. doi:10.1111/j.1540-

5915.2010.00304.x

Ballou, B., Heitger, D. L., \& Navynell, L. (2010). Creating effective dashboards (Cover Story). Strategic Finance, 91(9), 27-32. Retrieved from http://www.imanet.org/PDFs/Public/SF/2010_03/03_2010_ballou.pdf 
Baber, W. F., \& Bartlett, R. V. (1990). Matrix organization theory and environmental impact assessment. Social Science Journal, 27(3), 235. doi:10.1016/0362-3319(90)90023-D

Bateman, T. S., \& Snell, S. A. (2007). Management: Leading and collaborating in a competitive world (7th ed.). Boston, MA: McGraw Hill/Irwin.

Biesdorf, S., Court, D., \& Willmott, P. (2013). Big data: What's your plan? Mckinsey Quarterly, 2013(2), 40-51. Retrieved from http://www.mckinsey.com/insights/business_technology/big_data_whats_your_plan/big_data whats_y our plan

Brake, T. (2009). Where in the world is my team? Making a success of your virtual global workplace. San Francisco, CA: Jossey-Bass.

Brown, S. A., Dennis, A. R., \& Venkatesh, V. (2010). Predicting collaboration technology use: Integrating technology adoption and collaboration research. Journal of Management Information Systems, 27(2), 9-53. doi:10.2753/MIS0742-1222270201

Brikci, N. \& Green, J. (2007). A guide to using qualitative research methodology. Research Unit, London School of Hygiene and Tropical Medicine. Retrieved from http://fieldresearch.msf.org/msf/bitstream/10144/84230/1/Qualitative\%20research\%20methodology.pd $\underline{f}$

Christensen, L. B., Johnson, R. B., \& Turner, L. A. (2010). Research methods, design, and analysis (11th ed.). Boston, MA: Allyn \& Bacon.

Currier, G. (2010). Sharing knowledge in the corporate hive. Baseline, 2010 (104), 23-29 Retrieved from http://www.baselinemag.com/c/a/Business-Intelligence/Knowledge-Management-and-CollaborationCreate-Knowledge-Sharing-513230/

Daniela, M. D. (2013). The interdependence between management, communication, organizational behavior and performance. Cluj-Napoca University. Retrieved from http://steconomiceuoradea.ro/anale/volume/2013/n1/165.pdf

D'Urso, S. C., \& Rains, S. A. (2008). Examining the scope of channel expansion: A test of channel expansion theory. With new and traditional communication media. Management Communication Quarterly, 21(4), 486-507. Retrieved from http://www.communicationcache.com/uploads/1/0/8/8/10887248/examining the scope of channel_e xpansion_a test_of_channel_expansion_theory_with_new_and_traditional_communication_media.pdf

Eisenberg, J., Hyun-Jung, L., Bruck, F., Brenner, B., Cleas, Mironski, J., \& Bell, R. (2013). Can business schools make students culturally competent? Effects of cross-cultural management courses on cultural intelligence. Academy of Management Learning \& Education, 12(4), 603-621. doi:10.5465/amle.2012.0022

Elbashir, M., Collier, P., Sutton, S., Davern, M., \& Leech, S. (2013). Enhancing the business value of business intelligence: The role of shared knowledge and assimilation. Journal of Information Systems, 27(2), 87-105. doi:10.2308/isys-50563

Ennis, L., \& Tims, R. (2010). Harnessing the power of SharePoint ${ }^{\circledR}$ for library applications. Computers in Libraries, 30(5), 6-12. Retrieved from http://www.infotoday.com/cilmag/jun10/Ennis Tims.shtml

French, S. L., \& Holden, T. (2012). Positive organizational behavior: A buffer for bad news. Business Communication Quarterly, 75(2), 208-220. doi:10.1177/1080569912441823

Gartner. (2009, January 15). Gartner reveals five business intelligence predictions for 2009 and beyond. Gartner Newsroom. Retrieved from http://www.gartner.com/it/page.jsp?id=856714

Geczy, P., Izumi, N., \& Hasida, K. (2011). Foundations for effective portal service management. Global Journal of Business Research, 5(2), 131-141. Retrieved from http://papers.ssrn.com/sol3/papers.cfm?abstract id $=1874166$

Gudas, S. (2009). Enterprise knowledge modeling: Domains and aspects. Technological and Economic Development of Economy, 15(2), 281-293. doi:10.3846/1392-8619.2009.15.281-293 
Guillemette, M. G., \& Paré, G. (2012). Toward a new theory of the contribution of the IT function in organizations. MIS Quarterly, 36(2), 529-551. Retrieved from http://misq.org

Gulati, R., Wohlgezogen, F., \& Zhelyazkov, P. (2012). The two facets of collaboration: cooperation and coordination in strategic alliances. Academy of Management Annals, 6(1), 531-583. doi:10.1080/19416520.2012.691646

HyperOffice. (2013). HyperOffice collaboration made simple. Why hyperspace? Retrieved from http://www.hyperoffice.com/why-hyperoffice/

IBM. (n.d.). IBM® Connections. Retrieved from http://www-03.ibm.com/software/products/en/conn

Iles, A. (2011). Sociotechnical systems. In D. Southerton (Ed.), Encyclopedia of consumer culture (pp. 1344-1346). Thousand Oaks: SAGE Publications. doi: 10.4135/9781412994248.n506

Janićijević, N., \& Aleksić, A. (2007). Complexity of matrix organizations and problems caused by inadequate implementation. Ekonomski Anali / Economic Annals, 52(174-175), 28-44. doi:10.2298/EKA0775028J

Jansen, H. (2010). The logic of qualitative survey research and its position in the field of social research methods. Forum: Qualitative Social Research, 11(2), 2.1. Retrieved from http://www.qualitativeresearch.net/index.php/fqs/article/view/1450/2946

Jensen, M. L., Lowry, P., \& Jenkins, J. L. (2011). Effects of automated and participative decision support in computer-aided credibility assessment. Journal of Management Information Systems, 28(1), 201233. doi: 10.2753/MIS0742-1222280107

Jucevicius, R. (2011). Sourcing knowledge for the cluster or business system. Proceedings of the International Conference on Intellectual Capital, Knowledge Management and Organizational Learning, 284291. Retrieved from http://www.academia.edu/2115031

Kock, N. (2002). Evolution and media naturalness: A look at e-communication through Darwinian theoretical lens. ICIS Proceedings (Paper 34). Retrieved from http://aisel.aisnet.org/icis2002/34

Kock, N. (2008). E-collaboration and e-commerce in virtual worlds: The potential of second life and world of warcraft. International Journal of e-Collaboration, 4(3), 1-13. doi:10.1234/12345678

Krebbekx, W., Harting, J., \& Stronks, K. (2012). Does collaborative research enhance the integration of research, policy and practice? The case of the Dutch health broker partnership. Journal of Health Services Research \& Policy, 17(4), 219-229. doi:10.1258/jhsrp.2012.011135

Kwak, H. (2012). Self-disclosure in online media. International Journal of Advertising, 31(3), 485-510. doi:10.2501/IJA-31-3-485-510

Leedy, P. D., \& Ormrod, J. E. (2010). Practical research: Planning and design (9th ed.). Upper Saddle River, NJ: Prentice Hall.

Lees, I. (2011). Building teams for performance. Keeping Good Companies, 63(9), 562-565. Retrieved from http://www.governanceinstitute.com.au/

Magnusson, P., Westjohn, S. A., Semenov, A. V., Randrianasolo, A. A., \& Zdravkovic, S. (2013). The role of cultural intelligence in marketing adaptation and export performance. Journal of International Marketing, 21(4), 44-61. doi:10.1509/jim.13.0055

Martinez, F. J., Pastor, J. A., Rodriguez, J. V., Lopez, R., \& Rodriguez, J. R. (2011). New architectures for presenting search results based on web search engines users experience. Information Research: An International Electronic Journal, 16(1). Retrieved from http://files.eric.ed.gov/fulltext/EJ925590.pdf

Mataracioglu, T., \& Ozkan, S. (2011). Governing information security in conjunction with COBIT and ISO 27001. International Journal of Network Security and its Applications, 3(4), 111-116. doi:10.5121/ijnsa.2011.3410

McAuley, J., Duberley, J., \& Johnson, P. (2007). Organization theory: Challenges and perspectives. Upper Saddle River, NJ: Prentice Hall. 
McNurlin, B. C., Sprague, R. H., Jr., \& Bui, T. (2009). Information systems management in practice (8th ed.). Upper Saddle River, NJ: Prentice Hall.

Mishra, K., Boynton, L., \& Mishra, A. (2014). Driving employee engagement: The expanded role of internal communications. Journal of Business Communication, 51(2), 183-202. doi: $10.1177 / 2329488414525399$

Mládková, L. (2011). Management of knowledge workers. Economics and Management, 2011(16), 826831. Retrieved from http://www.ktu.lt/lt/mokslas/zurnalai/ekovad/16/1822-6515-2011-0826.pdf

Mor, S., Morris, M., \& Joh, J. (2013). Identifying and training adaptive cross-cultural management skills: The crucial role of cultural metacognition. Academy of Management Learning \& Education, 12(3), 453-475. doi:10.5465/amle.2012.0202

Morgan, T. R., Autry, C. W., \& Adams, F. G. (2012). Developing a returns competency: The influence of collaboration and IT capabilities. Society for Marketing Advances Proceedings, 54-55. Retrieved from http://www.marketingadvances.org/

Msanjila, S. S., \& Afsarmanesh, H. H. (2008). Trust analysis and assessment in virtual organization breeding environments. International Journal of Production Research, 46(5), 1253-1295. doi:10.1080/00207540701224350

Nemiro, J., Beyerlein, M., Bradley, L., \& Beyerlein, S. (Eds.). (2008). The handbook of high-performance virtual teams: A toolkit for collaborating across boundaries. San Francisco, CA: Jossey-Bass.

Nicolau, F. (2013). Educational collaboration aiming at effective communication. Elearning \& Software for Education, 2013(2), 412-415. doi:10.12753/2066-026X-13-175

Oliver, D., \& Lainhart, J. (2011). Delivering business benefits with COBIT: An introduction to COBIT 5. COBIT Focus, 2011(3), 1-3. Retrieved from http://www.isaca.org/knowledge-center/cobit/cobitfocus/documents/cobit-focus-vol-3-2011.pdf

Paschke, A. \& Martin, B. (2008). Knowledge representation concepts for automated SLA management. Decision Support Systems, 46, 187-205. doi:10.1016/j.dss.2008.06.008

Peppard, J., Edwards, C., \& Lambert, R. (2011). Clarifying the ambiguous role of the CIO. MIS Quarterly Executive, 10(1), 31-44. Retrieved from http://www.som.cranfield.ac.uk/som/dinamiccontent/media/ISRC/Clarifying\%20the $\% 20$ Ambiguous $\% 20$ Role $\% 20$ of $\% 20$ the $\% 20 \mathrm{CIO}$.pdf

QSR. (2013). NVivo10®. Retrieved from http://www.qsrinternational.com/products_nvivo.aspx

QSR. (2014). NVivo10®. Getting started guide. Retrieved from http://download.qsrinternational.com/Document/NVivo10/NVivo10-Getting-Started-Guide.pdf

Rapoza, J. (2010). SharePoint ${ }^{\circledR}$ moves into the modern Web age. Eweek, 27(2), 20. Retrieved from http://www.eweek.com/c/a/Enterprise-Applications/LABS-GALLERY-Microsoft-SharePoint-2010Beta-Shows-Platform-Joining-Modern-Web-Age-840042/?mchk=1

Sarkus, D. (2013). Collaboration or cooperation. Industrial Safety \& Hygiene News, 47(7), 46. Retrieved from http://www.highbeam.com/doc/1G1-342769884.html

Sawhney, T. (2008). Cultural intelligence and business behavior. ICFAI Journal of Soft Skills, 2(4), 31-37. Retrieved from http://ccm.sagepub.com/content/13/1/5.full.pdf + html

Shengbin, H., \& Bo, Y. (2011). The impact of technology selection on innovation success and organizational performance. I-Business, 3(4), 366-371. doi:10.4236/ib.2011.3404

Strang, A. J., Knott, B. A., Funke, G. J., Russell, S. M., Miller, B. T., Dukes, A. W., \& Bolia, R. S. (2011). Collaboration technologies improve performance and communication in air battle management. Military Psychology, 23(4), 390-409. doi:10.1080/08995605.2011.589348

Strikwerda, J. J., \& Stoelhorst, J. W. (2009). The emergence and evolution of the multidimensional organization. California Management Review, 51(4), 11-31. doi:10.2307/41166503 
SurveyMonkey. (2013). Pilot test tips: How to verify the design and settings. Retrieved from http://help.surveymonkey.com/articles/en_US/kb/Pilot-Test-Tips-How-to-verify-the-design-and$\underline{\text { settings }}$

Szczerbicki, E. (2006). Information and knowledge management: Advances, challenges, and critical issues. Cybernetics and Systems, 37(2/3), 93-95. doi:10.1080/01969720500425004

Thomas, R. L. (2011). Convergence: It's what's next in healthcare IT. Healthcare Financial Management, 65(1), 130-130, 132. Retrieved from http://www.hfma.org/Content.aspx?id=2909

Trist, E. (1981). The evolution of socio-technical systems. Retrieved from http://E Trist-sociotech.net

U.S. Fleet Cyber Command. (2012). Navy information dominance corps human capital strategy. Retrieved from http://www.public.navy.mil/fcc-c10f/Strategies/Forms/AllItems.aspx

Van der Land, S., Schouten, A. P., Van den Hooff, B., \& Feldberg, F. (2011). Modelling the metaverse: A theoretical model of effective team collaboration in 3D virtual environments. Journal of Virtual Worlds Research, 4(3), 1-16. Retrieved from https://journals.tdl.org/jvwr/index.php/jvwr/article/view/6126/5787

Waterson, P. E., Older Gray, M. T., \& Clegg, C. W. (2002). A sociotechnical method for designing work systems. Human Factors, 44(3), 376-376. doi:10.1518

Yang, X., \& Bernard, A. (2010). Knowledge value chain: An effective tool to measure knowledge value. International Journal of Computer Integrated Manufacturing, 23(11), 957-967. doi:10.1080/0951192X.2010.500677

Zadjabbari, B., \& Wongthongtham, P. (2009). Knowledge and trust issues for intellectual capital measurement. Proceedings of the European Conference on Intellectual Capital, 570-580. Reference from http://espace.library.curtin.edu.au/R/?func $=$ dbin-jump-full\&object_id $=132776 \&$ local base $=$ GEN01ERA02

Zawislak, P., Alves, A., Tello-Gamarra, J., Barbieux, D., \& Reichert, F. (2012). Innovation capability: From technology development to transaction capability. Journal of Technology Management \& Innovation, 7(2), 14-26. doi: 10.4067/S0718-27242012000200002

\section{Biographies}

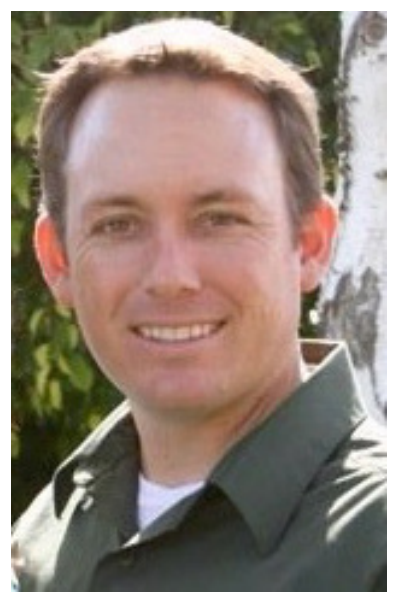

Dr. Ryan Wark is married and has three children. He maintains a position of Senior Information Technology Specialist with the United States Navy. In this role, he leads many organizational improvement initiatives. This includes the application of an Information Technology Infrastructure Library framework and the implementation of new collaboration technologies used by Navy scientists and engineers. Dr. Wark has also headed the Logistics and Fleet support for several Meteorology and Oceanography tactical information systems used by the Navy. Accolades include the Navy's Meritorious Civilian Service, Exemplary Achievement, and Lean Six Sigma Continuous Process Awards. His focus of study includes using information systems to achieve a Navy mission of Information Dominance. Prior to working with the Navy, Dr. Wark served in the United States Air Force. 


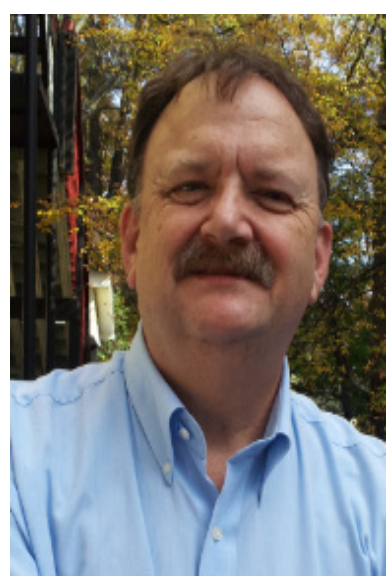

Dr. Jon Webber is married and has four children and a number of grandchildren. He is the President/CEO of Webber Impact Management, Inc., a global consulting and training firm specializing in ethics, leadership, team building, coaching, management, and organizational behavior. He is internationally recognized for his seminal work in common sense leadership and corporate social responsibility. He assists senior level managers and organizations in seeing the "big picture" of where they really are now and where they could be in the future if they dare dream the possibilities that are within their reach. Dr. Webber is involved in leadership development and research projects in Europe, Africa, and Asia. He has been a senior faculty member at many of the top ten online universities in the world. He is a published international author. 